\title{
Somatosensory evoked potentials in workers exposed to toluene and styrene
}

\author{
I Štětkářová, P Urban, B Procházka, E Lukáš
}

\begin{abstract}
Somatosensory evoked potentials (SEPs) were used to evaluate possible subclinical impairment of the nervous system due to occupational exposure to toluene and styrene. A group of 36 rotogravure printers with severe exposure to toluene, 20 workers with severe exposure to styrene in a glass laminate manufacturing plant, and a comparison group of healthy subjects were studied. The severity of exposure was documented by measurements of toluene and styrene concentrations in breathing zone air, by hippuric acid concentration in urine in the group exposed to toluene, and by urinary mandelic acid concentration in the group exposed to styrene. Somatosensory evoked potentials were measured by stimulation of the median nerve at the wrist and the tibial nerve at the ankle. Peripheral conduction velocities (CVs) in both extremities and central conduction time (CCT) after tibial nerve stimulation were significantly decreased in both exposed groups. Significantly prolonged latencies of peripheral and cortical SEPs to median nerve stimulation as well as cortical SEPs to tibial nerve stimulation were found in workers exposed to styrene. Some abnormalities in SEPs at peripheral or spinal and cortical levels were found in eight workers exposed to toluene and six workers exposed to styrene. Of these, in three workers exposed to toluene and two to styrene increased CCT and delayed latencies of cortical responses at normal conduction values in the periphery were found. $A$ trend for increased frequency of abnormal SEPs with duration of exposure to toluene and styrene and alcohol abuse was found.
\end{abstract}

Department of Neurology, Postgraduate Medical School, Thomayer's Hospital, Prague, Czechoslovakia I Štětkár̆ová

Center of Industrial Hygiene and Occupational Diseases, National Institute of Health, Prague, Czechoslovakia

P Urban, B Procházka, E Lukáš
Abnormalities in SEPs in the exposed groups are most probably of multifactorial origin. Central SEP abnormalities in both exposed groups could indicate early signs of subclinical dysfunction at spinal and cortical levels and could be due to toluene or styrene exposure probably potentiated by alcohol consumption in the group exposed to toluene.

(British fournal of Industrial Medicine 1993;50:520-527)

The development of neurophysiological and neurochemical tests enables detection of neurotoxic effects at early stages and at low levels of exposure to different chemicals. Consequently chronic and less readily noticed adverse effects caused by longterm exposure have become of primary interest in occupational medicine especially where improvements of working conditions have led to decreased prevalence of acute and severe intoxication.

Toluene and styrene are well known neurotoxic organic solvents widely used in industrial and occupational settings. Their adverse acute and chronic effects on the morphology and function of the nervous system have been documented in several experimental and clinical studies. ${ }^{1-7}$ Various psychological and neurophysiological tests including electroencephalography, electromyography, and evoked potentials have been used for detection of possible impairment of the nervous system. Sensory evoked potentials, one of the non-invasive neurophysiological methods, enables the evaluation of functional integrity of all sensory pathways ${ }^{8-9}$ and it reflects activity at the level of neural generators from the peripheral end organ to the higher integrative centres of the brain. Several authors ${ }^{10-15}$ recommend the use of this method in neurotoxicology for detection of possible subclinical lesions of the nervous system. Various reports have described changes in visual evoked potential and brainstem auditory evoked potential due to acute and chronic exposure to organic solvents in experimental ${ }^{16-18}$ as well as in clinical ${ }^{19-20}$ studies.

In our study we used somatosensory evoked potentials (SEPs) for detection of possible subclinical impairment at the somatosensory pathway. 
This method enables a more exact localisation of expected dysfunction at peripheral, subcortical, and cortical levels.

\section{Materials and methods}

\section{STUDY POPULATIONS}

Group 1: exposed to toluene

Thirty six male rotogravure printers exposed to toluene in a polygraphic plant in Prague were enrolled. Their age ranged from 19 to 68 (mean 39 (SD12)) years. Most (75\%) were exposed to toluene for more than five years, with a maximum of 41 years (mean 12 years).

The extent of exposure was documented by (1) measurement of toluene concentration in the worker's breathing zone air. The mean value for the period $1977-87$ was about $2000 \mathrm{mg} / \mathrm{m}^{3}$ (threshold limit value $200 \mathrm{mg} / \mathrm{m}^{3}$ with a peak of $\left.1000 \mathrm{mg} / \mathrm{m}^{3}\right)$; (2) by hippuric acid concentration in urine measured in samples collected at the end of each shift. This test represents a biological marker for toluene. The mean yearly value for the decade was about $45 \mathrm{mmol} / \mathrm{l}$ after correction for $1020 \mathrm{~g} / \mathrm{l}$ standard density of urine. The normal limit is $14 \mathrm{mmol} / 1$.

\section{Group 2: exposed to styrene}

A group of 20 workers exposed to styrene in a factory making glass laminates was studied. This group consisted of five men aged 24 to 48 (mean 38(SD9)) years and 15 women aged 31 to 51 (mean 45 (SD6)) years. Most (85\%) were exposed to styrene for more than five years with a maximum of 22 years (mean 11 years). The exposure was documented by measurement of styrene concentration in the worker's breathing zone air and by mandelic acid concentration in urine as a biological marker for styrene. The mean year round value of styrene concentration in the air for the period 1980-9 ranged from 140 to $570 \mathrm{mg} / \mathrm{m}^{3}$ with a peak of $1250 \mathrm{mg} / \mathrm{m}^{3}$. The overall limit per eight hour shift is $200 \mathrm{mg} / \mathrm{m}^{3}$ with a maximal peak of $1000 \mathrm{mg} / \mathrm{m}^{3}$. Mandelic acid concentration in urine (samples taken at the end of the shift) ranged from 200 to $1400 \mu \mathrm{mol} / \mathrm{mmol}$ creatinine (biological limit is $246 \mu \mathrm{mol} / \mathrm{mmol}$ of creatinine).

A detailed history was obtained followed by neurological examination and testing of SEPs for each worker.

\section{Group 3: the comparison group}

The comparison consisted of 30 male (aged 16 to 64, mean 31 (SD11) years) and 40 female volunteers (aged 16 to 52, mean 32 (SD11) years) without known exposure to any neurotoxic agent. They had no history of or clinical findings of neurological disorders during examination.
MEASUREMENTS OF SOMATOSENSORY EVOKED

POTENTIALS

A Neuromatic 2000 DISA was used for SEP examination. Electric stimuli $(0.2 \mathrm{~ms}$ duration constant current square wave pulses, frequency $5 \mathrm{~Hz}$ ) were delivered to the right median and tibial nerves at the wrist and at the ankle respectively, at an intensity producing a visible thumb or toe twitch. The stimulating electrode was positioned with the cathode placed proximally. The low frequency filter of the amplifier was set at $10 \mathrm{~Hz}$ and the high frequency filter at $5000 \mathrm{~Hz}$. Evoked responses from 300 to 600 stimuli were averaged and each procedure was repeated. The analysis time was $20-50 \mathrm{~ms}$ in the right median nerve stimulation and $50-100 \mathrm{~ms}$ in tibial nerve stimulation.

The derivations used in the right median and tibial nerve stimulation were: Erb's point-Fz, C6$\mathrm{Fz}, \mathrm{C} 3$ '-Fz, L1-Th12, and $\mathrm{Cz}^{\prime}-\mathrm{Fz}$.

The following peak latencies, amplitudes, peripheral conduction time (PCT), and central conduction time (CCT) were calculated: N10, $\mathrm{N} 13, \mathrm{~N} 20$ and late cortical components, N10-N13 (PCT), N10-N20, N13-N20 (CCT) for median nerve stimulation; N22, N33, P40 and late cortical components, N22-N33 and N22-P40 (CCT) for tibial nerve stimulation, ${ }^{21}$ and amplitudes of primary cortical responses (N20 and P40). ${ }^{22}$ The median nerve $\mathrm{CV}$ was calculated as the distance from the stimulating cathode to Erb's point over latency of $\mathrm{N} 10 .{ }^{23}$ The tibial nerve $\mathrm{CV}$ was calculated as the distance from $\mathrm{L} 1$ to the floor over latency of N22. Figure 1 shows samples of normal median and tibial nerve SEPs.

\section{STATISTICAL ANALYSIS}

The significance of differences of the mean values of study variables in the exposed and control groups were calculated with the Student's $t$ test. Differences in latencies related to sex, age, height, and study group were assessed by multiple regression analysis. Where applicable the test for trend was used. ${ }^{27}$

\section{Results}

HISTORY AND CLINICAL NEUROLOGICAL EXAMINATION

In the workers exposed to toluene and styrene neurasthenic symptoms (for example, sleep disturbances, fatigue, occasional headache) occurred in $35 \%$ and $30 \%$ respectively. Mental disorders (forgetfulness, lability of mood, irritability) were reported in $5 \%$ and $10 \%$. Back pain was reported by $60 \%$ of the groups exposed to styrene, consisting predominantly of women, whereas only $20 \%$ of such discomfort occurred in the group exposed to toluene. This significant difference may be attributed to a different work load. In the group exposed 

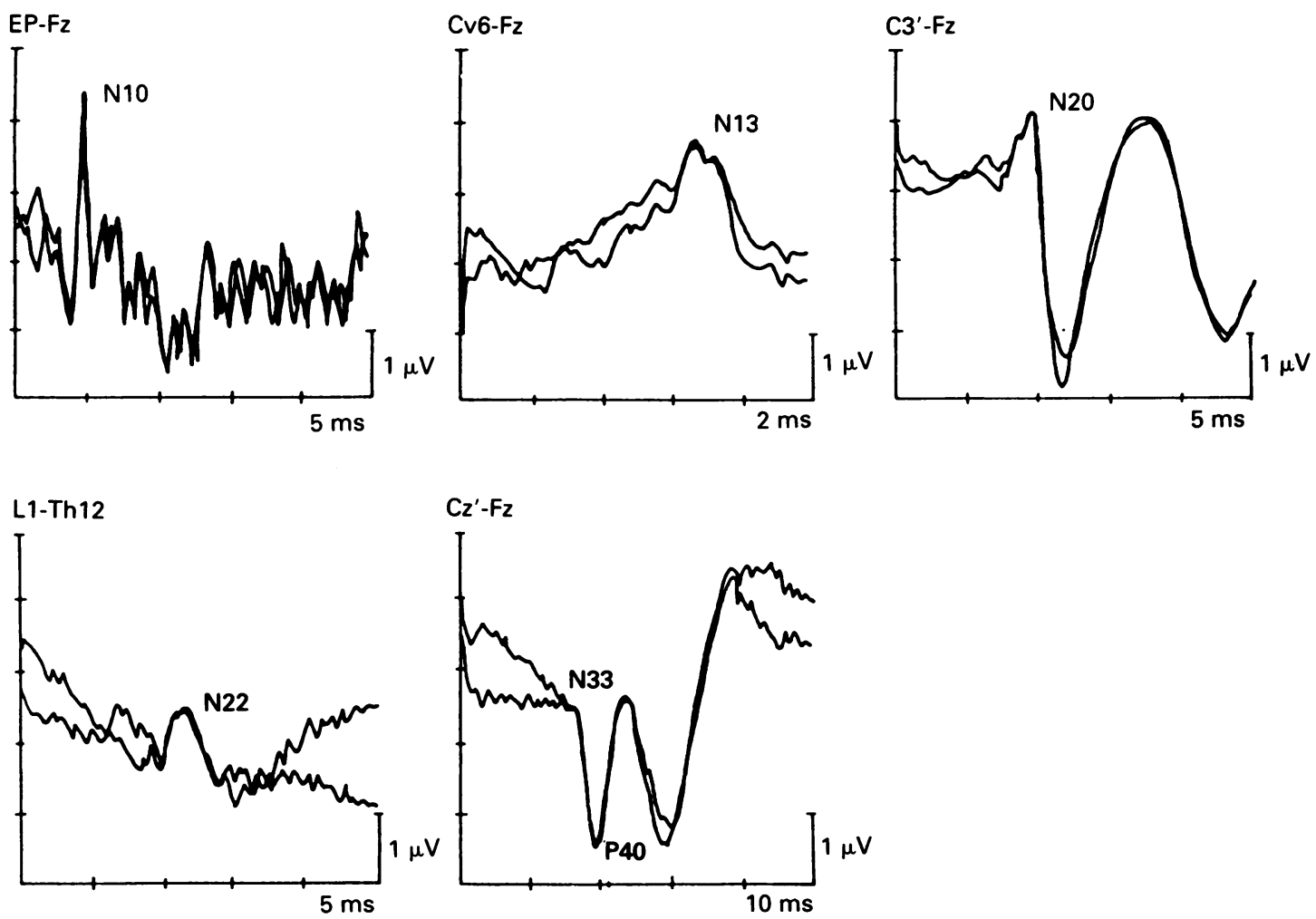

Figure 1 Normal SEP curves in a healthy subject. Peripheral (EP-Fz), cervical (Cv6-Fz), and cortical (C.3'-Fz) SEPs after stimulation of the median nerve at the wrist, and spinal (L1-Th12) and cortical (Cz'-Fz) SEPs after stimuiation of the tibial nerve were recorded. The major components are marked (28 year old woman, $180 \mathrm{~cm}$ height).

to styrene elbow pain was reported in $10 \%$ and paresthaesia of the second and third fingers of the right hand in $25 \%$ whereas no such complaints occurred in the other exposed group.

Findings of neurovegetative lability (finger and eyelid tremors, increased dermographism, hyperreflexia, hyperhidrosis) were found in $50 \%$ of both exposed groups. Bilaterally decreased Achilles tendon reflexes were found in $20 \%$ of the group exposed to toluene and $10 \%$ of group exposed to styrene. Slight carpal tunnel signs were found in $15 \%$ of workers exposed to styrene. Subjective symptoms were not reported by $50 \%$ of workers exposed to toluene and $25 \%$ of workers exposed to styrene.

Drinking habits for all groups were categorised by the reported alcohol intake (table 1). Excessive daily intake of alcohol did not occur in any person of the comparison group. Thirteen workers exposed to toluene reported a daily alcohol intake exceeding $50 \mathrm{mg}$.

ASSESSMENT OF SEP FINDINGS

Differences in latencies for sex, age, height, and left and right site were computed for the comparison group. For all components of latencies correlation with height was found to be highly significant after adjustment for other variables. Sex and site related differences were significant in most cases. Consequently the comparison group was subdivided into men and women and the SEP responses from the right side were used as standards. There were no height related changes for conduction times. For standard evaluation of differences in latencies the height was used. There were statistically significant differences in length of arms and legs between exposed and comparison groups. Therefore extrapolation from latency of N10 and N22 was used for computation of conduction velocity. For interpretation of the results of this study, the SEP response was considered abnormal if at least one of the following variables exceeded its $95 \%$ reference range: wave latencies (peripheral $\mathrm{N} 10$ and spinal N22, cervical N13, cortical N20, N33, and P40 waves), conduction times (PCT, CCT), and conduction velocities. The amplitudes of normal cortical SEP components showed considerable variability; consequently the amplitude was not used for interpretation of an abnormal response. ${ }^{25} \mathrm{We}$ divided the abnormal SEP findings into three categories: the 
Table 1 Daily alcohol intake in the comparison group and in workers exposed to toluene or styrene

\begin{tabular}{lcccccc}
\hline & \multicolumn{2}{l}{$\begin{array}{l}\text { Comparison } \\
\text { group }\end{array}$} & \multicolumn{2}{l}{$\begin{array}{l}\text { Exposed to } \\
\text { toluene }\end{array}$} & \multicolumn{3}{l}{$\begin{array}{l}\text { Exposed to } \\
\text { styrene }\end{array}$} \\
\cline { 2 - 7 } $\begin{array}{l}\text { Daily alcohol } \\
\text { intake (mg) }\end{array}$ & No & $(\%)$ & No & $(\%)$ & No & $(\%)$ \\
\hline$<20 \mathrm{mg}$ & 64 & $(92)$ & 14 & $(39)$ & 16 & $(80)$ \\
$20-50 \mathrm{mg}$ & $5^{\star}$ & $(7)$ & 9 & $(25)$ & $2 \dagger$ & $(10)$ \\
$>50 \mathrm{mg}$ & 1 & $(1)$ & 13 & $(26)$ & 2 & $(10)$ \\
\hline
\end{tabular}

Note: ${ }^{\star}$ Two women; tone woman

"peripheral" type consisting mainly of decreased peripheral $\mathrm{CV}$ with corresponding prolongation of peripheral N10 and spinal N22 as well as decrease in their amplitude. The "central" type was characterised mostly of delayed CCT, prolongation of cortical latencies, and decrease of their amplitude with normal responses at the periphery. The third type was a combination of both peripheral and central types.

\section{The group exposed to toluene}

Eight persons exposed to toluene had abnormal SEPs. Of these, three workers had an impairment of the peripheral NS ("peripheral" type) (CV for median nerve $55.4 \mathrm{~m} / \mathrm{s}$, CV for tibial nerve $44.4 \mathrm{~m} / \mathrm{s}$ ). Three workers had an impairment of the central segment ("central" type) (CCT for tibial nerve $15 \cdot 3 \mathrm{~m} / \mathrm{s}$ ). Abnormalities of both peripheral and central SEP pathways were found in two workers (CV for median nerve $51.8 \mathrm{~m} / \mathrm{s}, \mathrm{CV}$ for tibial nerve $41.7 \mathrm{~m} / \mathrm{s}$, CCT for tibial nerve $15.0 \mathrm{~ms}$ ). Table 2 shows the correlation of abnormal SEPs with duration of exposure to toluene. There was a significant trend of increasing frequency of abnormal SEPs with duration of exposure to toluene. A similar correlation was found with alcohol intake (table 3): again a significant trend was found between alcohol intake and abnormal SEPs. Figure 2 shows an abnormal SEP finding. Tables 4 and 5 present comparisons of mean values of median and tibial nerve SEPs in the group of workers exposed to toluene, and in the comparison group. The results were similar after adjustment for the potential confounding variables sex, age, height, and differences among groups in multiple regression analysis. Decreased peripheral CVs for median and the tibial nerve stimulation were statistically significant. Delayed CCT for tibial nerve stimulation was also significant.

\section{The group exposed to styrene}

Six persons had abnormal SEPs. Of these, two had SEP abnormalities of the "peripheral" type (CV for median nerve $56.4 \mathrm{~m} / \mathrm{s}, \mathrm{CV}$ for tibial nerve $49.2 \mathrm{~m} / \mathrm{s}$ ), two had SEP abnormality of the "central" type (CCT for tibial nerve $20.4 \mathrm{~m} / \mathrm{s}$ ), and two subjects had an impairment in all SEP pathways (CV for median nerve $56.4 \mathrm{~m} / \mathrm{s}, \mathrm{CV}$ for tibial nerve $49.2 \mathrm{~m} / \mathrm{s}$, CCT for tibial nerve $14.8 \mathrm{~m} / \mathrm{s}$ ). The trend in correlation of SEP abnormalities with duration of exposure to styrene did not reach statistical significance (table 6). Increased alcohol intake in this group occurred in four persons only (see table 1); alcohol intake did not correlate with response to styrene. Figure 3 shows an example of abnormal SEP curves.

Tables 4 and 5 show the median and tibial nerve SEPs in the workers exposed to styrene and their comparison group. The major significant abnormalities were prolonged latencies of $\mathrm{N10}, \mathrm{P} 13$, and cortical components of N20, P22, and P27 for median nerve stimulation and N33 and late cortical components for stimulation of the tibial nerve. Decreased peripheral CV for median and tibial nerve stimulation and delayed CCT for the tibial nerve stimulation were also significant.
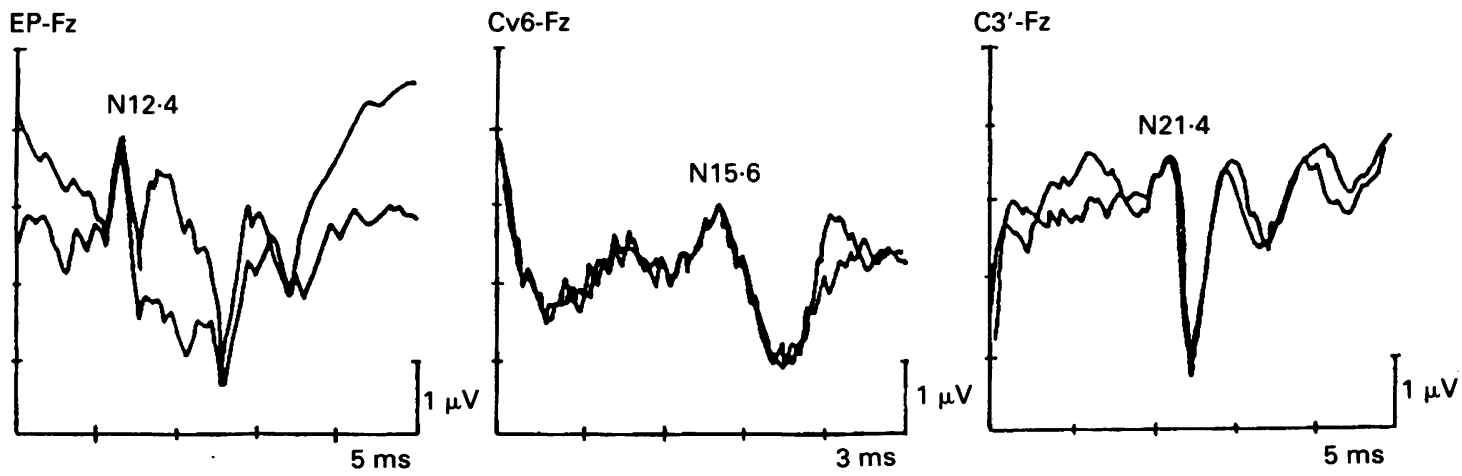

Figure 2 Abnormal SEP curves after median nerve stimulation showing an impairment of the peripheral part of the somatosensory pathway. Prolonged latency of N10 (12.4 ms) is followed by prolongation of cervical N13 (15.6 ms) and cortical N20 (21.4 ms) responses. Conduction times (N10-N13 and N13-N20 are in the normal range (35 year old male alcohol abuser, $180 \mathrm{~cm}$ height, exposed to toluene for four years). 
Table 2 Abnormal SEP findings in relation to duration of exposure to toluene

\begin{tabular}{lllll}
\hline & \multicolumn{4}{l}{ Somatosensory evoked potentials } \\
\cline { 2 - 5 } Exposure $(y)$ & Normal & \multicolumn{2}{l}{ Abnormal } & \\
\hline $0-4$ & No & 9 & No & (\%) \\
$5-14$ & 11 & 1 & $(10)$ & \\
15 and more & 5 & 3 & $(21)$ & $\mathrm{t}=2.11^{\star}$ \\
\hline
\end{tabular}

^Test of trend was used

Table 3 Abnormal SEP findings in relation to daily intake of alcohol in the group exposed to toluene

\begin{tabular}{lllll}
\hline & \multicolumn{4}{l}{ Somatosensory evoked potentials } \\
\cline { 2 - 5 } $\begin{array}{l}\text { Daily alcohol } \\
\text { intake (in mg) }\end{array}$ & Normal & \multicolumn{3}{l}{ Abnormal } \\
No & No & (\%) & \\
\hline$<20 \mathrm{mg}$ & 12 & 2 & $(17)$ & \\
$20-50 \mathrm{mg}$ & 7 & 2 & $(22)$ & $\mathrm{t}=2.06 \star$ \\
$>50 \mathrm{mg}$ & 6 & 7 & $(54)$ & $\mathrm{p}<0.01$ \\
\hline
\end{tabular}

*Test of trend was used

\section{Discussion}

An abnormal response of the nervous system to stimuli is non-specific for the aetiology of dysfunction. In our study abnormal SEPs were found in subjects exposed to severe exposure to toluene and styrene, mostly without any subjective complaints or objective neurological symptoms of impairment of the nervous system.

The median and tibial nerve SEPs in groups exposed to toluene or styrene showed a statistically significant decrease in peripheral CVs. Increased latencies of median SEP were found in workers exposed to styrene but not in workers exposed to toluene. These findings suggest impairment of the peripheral nervous system. Some authors consider such impairment to be due to chronic exposure to styrene. ${ }^{26}{ }^{27}$ Kovařík et al ${ }^{28}$ found slight distal sensitive motor neuropathies by electromyography in $28.5 \%$ of workers exposed to styrene. They excluded any other professional or non-professional causes of these electromyography findings. Cherry and Gautrin ${ }^{29}$ reported a mild sensory nerve conduction deficit increasing from $23 \%$ to $71 \%$ depending on exposure of less than $50 \mathrm{ppm}$ to more than $100 \mathrm{ppm}$ styrene. By contrast, Triebig et $a l^{30}$ found no significant differences in motor and sensory nerve conduction velocities between workers exposed to styrene and controls. Our group exposed to styrene consisted predominantly of women working daily with excessive strain on their right hand. The abnormal findings could be because women may be more sensitive to adverse effects of toxic substances or excessive strain on the hands combined with neurotoxic exposure could lead to compressive ischaemic neuropathy (for example, carpal tunnel syndrome). A direct neurotoxic effect of styrene on the peripheral nervous system is also possible.

The workers exposed to toluene had more SEPs with decreased peripheral CVs during stimulation of the tibial nerve. These findings, with slight clinical signs of impairment of the peripheral nervous system (hyporeflexia of Achilles tendon reflexes) suggest an incipient polyneuropathy associated with prolonged exposure to other neurotoxic substances, for example, alcohol. Increased alcohol consumption among workers exposed to organic solvents is well known. ${ }^{331} \mathrm{~A}$ possible interaction of both neurotoxic substances in humans is supported by a study of metabolic interaction between toluene and ethanol in rabbits, which showed an inhibitory effect of ethanol on excretion of toluene. ${ }^{32}$

Significant prolongation of CCT occurred after stimulation of the tibial nerve in both exposed groups. There were no significant changes registered for CCT of median nerve SEPs. Similar changes in SEPs were reported in chronic alcoholic patients. ${ }^{33}$ The SEP pathway consists of very long fibres from periphery through the dorsal columns and therefore it is considered to be more vulnerable to exposure to neurotoxic substances..$^{153435} \mathrm{Chang}^{36}$ stated that both the absolute latencies and CCT in median nerve SEPs were delayed in cases of sub-

Table 4 Somatosensory evoked potentials (mean (SD)) to median nerve stimulation in men exposed to toluene, woman exposed to styrene, and their corresponding comparison groups

\begin{tabular}{|c|c|c|c|c|c|c|c|c|}
\hline Parameter & No & Comparisons & No & $\begin{array}{l}\text { Exposed to } \\
\text { toluene }\end{array}$ & No & Comparisons & No & $\begin{array}{l}\text { Exposed to } \\
\text { styrene }\end{array}$ \\
\hline $\begin{array}{l}\text { N10 (ms) } \\
\text { N13 (ms) } \\
\text { N20 (ms) } \\
\text { P22 (ms) } \\
\text { P27 (ms) } \\
\text { N35 (ms) } \\
\text { P45 (ms) } \\
\text { Ampl. N20 (uV) } \\
\text { N10-N13 (ms) } \\
\text { N13-N20 (ms) } \\
\text { N10-N20 (ms) } \\
\text { Peripheral CV }(\mathrm{m} / \mathrm{s})\end{array}$ & $\begin{array}{l}23 \\
23 \\
29 \\
28 \\
22 \\
24 \\
26 \\
29 \\
23 \\
23 \\
23 \\
23\end{array}$ & $\begin{array}{r}10.3(0.7) \\
14.0(0.7) \\
19.7(0.9) \\
23.2(0.9) \\
28.2(2.1) \\
35.1(2.3) \\
43.7(2.2) \\
5.4(3.3) \\
3.6(0.4) \\
5.8(0.6) \\
9.2(0.5) \\
65.1(3.1)\end{array}$ & $\begin{array}{l}35 \\
35 \\
35 \\
35 \\
27 \\
33 \\
24 \\
36 \\
35 \\
35 \\
35 \\
35\end{array}$ & $\begin{array}{l}10.5(0.8) \\
14.1(0 \cdot 8) \\
19.7(0 \cdot 8) \\
23.4(0 \cdot 8) \\
28.3(2 \cdot 4) \\
34.9(2 \cdot 0) \\
43.7(2 \cdot 6) \\
4.0(2 \cdot 2) \\
3.6(0 \cdot 6) \\
5.6(0.6) \\
9.4(0.6) \\
59.4(4 \cdot 6)^{\star \star}\end{array}$ & $\begin{array}{l}32 \\
30 \\
40 \\
40 \\
30 \\
36 \\
26 \\
40 \\
26 \\
30 \\
30 \\
28\end{array}$ & $\begin{array}{r}9.3(0.4) \\
12.5(0.5) \\
18.2(0.7) \\
21.3(0.9) \\
25.9(1.6) \\
34.5(4.0) \\
43.8(2.9) \\
4.4(2.4) \\
3.2(0.3) \\
5.7(0.5) \\
8.9(0.5) \\
63.1(2.5)\end{array}$ & $\begin{array}{r}15 \\
15 \\
15 \\
12 \\
9 \\
10 \\
11 \\
15 \\
15 \\
15 \\
15 \\
15\end{array}$ & $\begin{array}{l}9.7(0.5)^{\star} \\
13.0(0.6)^{\star} \\
18.9(1.0)^{\star} \\
21.8(0.9) \\
28.0(2.7)^{\star} \\
34.5(4.0) \\
40.2(4.4)^{\star} \\
4.2(3.0) \\
3.3(0.5) \\
5.9(1.0) \\
9.2(0.6) \\
58.7(2.1)^{\star \star}\end{array}$ \\
\hline
\end{tabular}


Table 5 Somatosensory evoked potentials to tibial nerve stimulation in men exposed to toluene, women exposed to styrene, and their corresponding comparison groups

\begin{tabular}{|c|c|c|c|c|c|c|c|c|}
\hline Parameter & No & Comparisons & No & $\begin{array}{l}\text { Exposed to } \\
\text { toluene }\end{array}$ & No & Comparisons & No & $\begin{array}{l}\text { Exposed to } \\
\text { st_rene }\end{array}$ \\
\hline $\begin{array}{l}\text { N22 (ms) } \\
\text { N33 (ms) } \\
\text { P40 (ms) } \\
\text { N50 (ms) } \\
\text { P70 (ms) } \\
\text { N80 (ms) } \\
\text { Ampl. N20 ( } / \mathrm{V}) \\
\text { N22-N33 (ms) } \\
\text { N22-P40 (ms) } \\
\text { Peripheral CV }(\mathrm{m} / \mathrm{s})\end{array}$ & $\begin{array}{l}24 \\
28 \\
28 \\
26 \\
26 \\
26 \\
25 \\
24 \\
24 \\
24\end{array}$ & $\begin{array}{l}23 \cdot 1(1 \cdot 4) \\
34 \cdot 5(2 \cdot 1) \\
41 \cdot 0(2 \cdot 1) \\
49 \cdot 4(2 \cdot 3) \\
61 \cdot 3(2 \cdot 7) \\
75 \cdot 1(6 \cdot 3) \\
2 \cdot 2(1 \cdot 1) \\
11 \cdot 1(1 \cdot 2) \\
17 \cdot 2(1 \cdot 7) \\
49.5(2 \cdot 2)\end{array}$ & $\begin{array}{l}19 \\
34 \\
34 \\
34 \\
34 \\
33 \\
34 \\
18 \\
18 \\
19\end{array}$ & $\begin{array}{l}23.8(1.6) \\
36.0(2 \cdot 4) \\
41.4(2 \cdot 6) \\
50.3(2.9) \\
61.7(3.4) \\
75.9(4 \cdot 4) \\
2.1(1 \cdot 1) \\
13.0(1.9)^{\star} \\
18.4(2.0) \\
47.0(3.0)^{\star \star}\end{array}$ & $\begin{array}{l}40 \\
40 \\
40 \\
38 \\
40 \\
40 \\
40 \\
39 \\
35 \\
28\end{array}$ & $\begin{array}{r}21 \cdot 7(1 \cdot 6) \\
32.6(1 \cdot 7) \\
38 \cdot 1(2 \cdot 7) \\
46 \cdot 4(3 \cdot 3) \\
57 \cdot 8(3 \cdot 6) \\
74 \cdot 1(6 \cdot 1) \\
2 \cdot 2(1 \cdot 1) \\
10.8(1 \cdot 2) \\
16.4(2 \cdot 0) \\
50.5(2 \cdot 4)\end{array}$ & $\begin{array}{l}15 \\
15 \\
14 \\
12 \\
12 \\
12 \\
12 \\
13 \\
12 \\
13\end{array}$ & $\begin{array}{l}22: \cdot 2(1 \cdot 2) \\
35 \cdot 0(2 \cdot 2)^{\star} \\
39 \cdot 5(2 \cdot 2) \\
48 \cdot 4(3 \cdot 4) \\
59.5(2 \cdot 7) \\
76.0(3 \cdot 5) \\
1.7(1 \cdot 1) \\
12 \cdot 8(2 \cdot 3) \\
17 \cdot 1(2 \cdot 5) \\
48 \cdot 3(2 \cdot 9)^{\star \star}\end{array}$ \\
\hline
\end{tabular}

${ }^{\star} \mathrm{p}<0.05 ;{ }^{\star \star} \mathrm{p}<0.01$.

Table 6 Abnormal SEP findings in relation to duration of exposure to styrene

\begin{tabular}{cllll}
\hline & \multicolumn{3}{l}{ Somatosensory evoked potentials } \\
\cline { 2 - 5 } Exposure $(y)$ & Normal & \multicolumn{2}{l}{ Abnormal } & \\
\hline $0-4$ & No & No & $(\%)$ & \\
$5-14$ & 3 & 0 & $(0)$ & \\
$>15$ & 2 & 5 & $(42)$ & $\mathrm{t}=1 \cdot 56^{\star}$ \\
\hline
\end{tabular}

*Test of trend was used

clinical and n-hexane polyneuropathy. The same author interpreted the decreased CCT as electrophysiological evidence for a neurotoxic effect of n-hexane on the spinal cord or the brainstem. Kokubun et $\mathrm{l}^{37}$ reported similar delayed CCT during stimulation of the tibial nerve in chronic alcoholic patients with or without polyneuropathy and

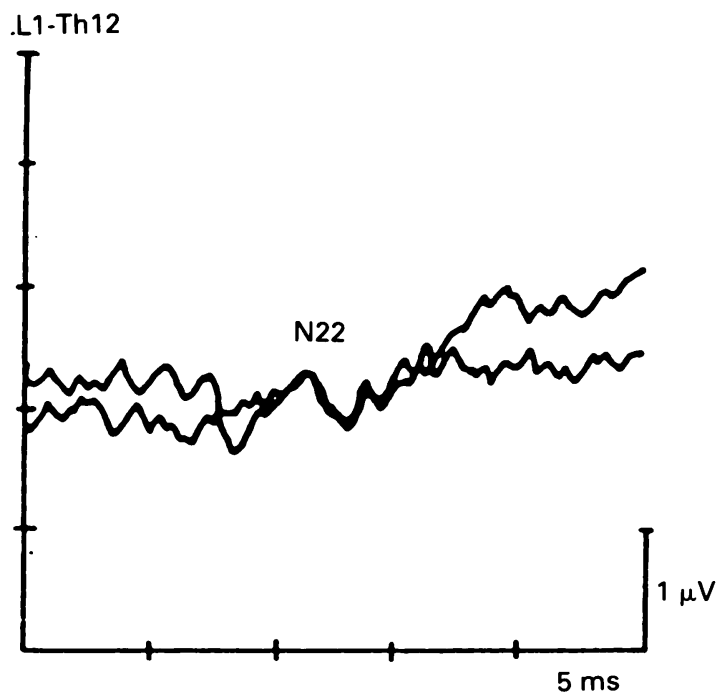

suggested that the impairment of posterior columns and brainstem could be due to ethanol myelopathy. Moller et $\mathrm{al}^{38}$ reported abnormalities in the central auditory pathways in workers exposed long-term to styrene. In our study both exposed groups showed an impairment of spinal or subcortical somatosensory pathways. This could be related to a neurotoxic effect of organic solvent, or ethanol, or both on dorsal columns or brainstem.

Hazemann et al ${ }^{39}$ found similar SEP findings in workers exposed to a mixture of organic solvents (mean exposure duration was 12 years). Decreased peripheral nerve $\mathrm{CV}$, slight increased latencies of late cortical components (N20, P22, N35) after stimulation to the median nerve, and late cortical components (P39, N50) after stimulation of the tibial nerve were obtained. The duration of exposure and its effect on SEP was not reported.

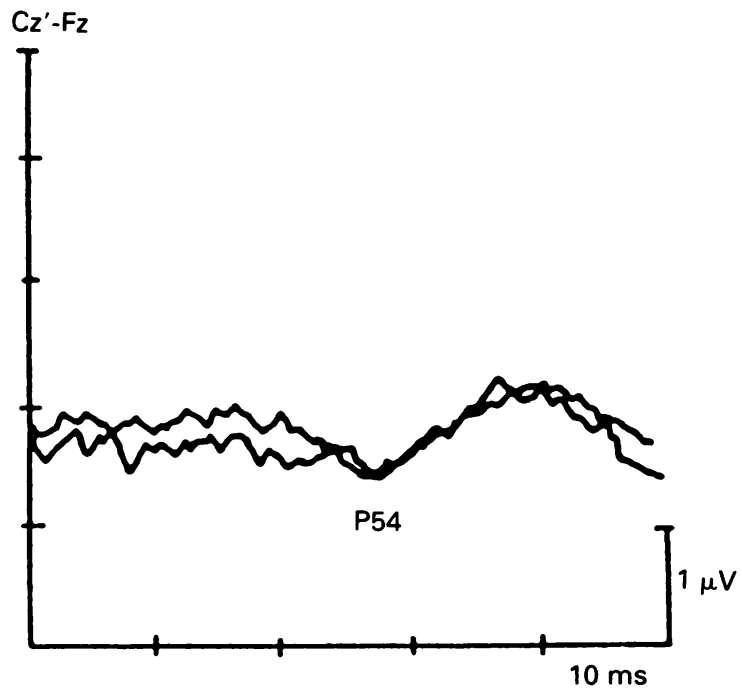

Figure 3 Abnormal SEP curves after tibial nerve stimulation showing an impairment of the central part of the somatosensory pathway. Spinal response $\mathrm{N} 22(22 \mathrm{~ms})$ is in the normal range. Abnormal prolongation of latency of cortical response P40 (54 $\mathrm{ms}$ ) with deformation of waveform and abnormal prolongation of central conduction times N22-P40 (32 ms) are presented (43 year old woman, $154 \mathrm{~cm}$ height, occasionally abusing alcohol, with a history of 14 years exposure to styrene). 
Nevertheless we were able to show a significant correlation of the duration of exposure to the organic solvent or to alcohol intake with abnormal SEP findings.

Prolonged latencies and reduced amplitudes of cortical SEP responses have been reported by several authors. Langauer-Lewowicka et $a l^{40}$ found prolonged latency and increased amplitude of N20 in workers exposed to carbon disulphide. On the other hand, Mutti et al ${ }^{41}$ showed significantly prolonged latencies of $\mathrm{N} 20$ and $\mathrm{N} 26$ in 15 women exposed to $n$-hexane but the late phase (N41-N75) of cortical responses after stimulation of the median nerve led to decreased amplitudes. In our study there was a trend towards the prolongation of latencies of cortical SEP components but it did not reach statistical significance. The neurotoxic effect of styrene and toluene on the central nervous system is well known. The neurochemical and structural bases in humans are not known. Rosengren and $\mathrm{Haglid}^{42}$ reported, from animal study, that exposure to styrene at moderate concentrations induced regional and long lasting astroglial reactions that served as an indicator of solvent induced brain damage. In rabbits a decrease in striatal concentration of dopamine due to exposure to styrene was shown. ${ }^{43} \mathrm{~A}$ role for toluene in the induction of oxidative stress in the central nervous system was reported. ${ }^{44}$ Rosenberg et al ${ }^{45}$ showed diffuse changes in white matter of the central nervous system by magnetic resonance imaging in toluene abusers. Abnormal cortical SEP responses detected in our workers could be interpreted as early signs of toxic encephalopathy due to chronic exposure to neurotoxins (the organic solvent syndrome $\left.^{46}\right)$.

The presented study shows evidence of functional impairment at all somatosensory pathways indicative of potential toxic polyneuropathy, myelopathy, or encephalopathy due to chronic exposure to neurotoxic agents (organic solvents, alcohol, a combination of both, predisposition, etc.). The SEP seems to be a useful method for screening and monitoring workers exposed to neurotoxic substances and should be included in the battery of electrophysiological tests to increase the sensitivity of detection of early dysfunction of the nervous system. ${ }^{47}$

We express our sincere appreciation to Dr E Adam for his helpful review and comments.

Requests for reprints to: Ivana Štětkářová, $M D$, Department of Neurology, Thomayer's Hospital - Postgraduate Medical School, Videnska 800, 14000 Prague 4, Czechoslovakia.

1 Baelum J, Lundgvist GR, Molhave L, Andersen NT. Human response to varying concentrations of toluene. Int Arch Occup Environ Health 1990;62:65-71.
2 Baker EL, Smith TJ, Landrigan PJ. The neurotoxicity of industrial solvents: a review of the literature. $A m$ f Ind Med 1985;8:207-17.

3 Juntunen J, Matikainen E, Antti-Poika M, Suorante H, Valle $M$. Nervous system effects of long-term occupational exposure to toluene. Acta Neurol Scand 1985;72:512-7.

4 National Institute of Occupational Safety and Health. Organic solvent neurotoxicity. Current intelligence bulletin 48. Cincinnati: NIOSH, 1987;3:1-5.

5 World Health Organisation. Styrene. Environmental health criteria 26. Geneva: WHO, 1983:73-6.

6 World Health Organisation. Toluene. Environmental Health Criteria 52. Copenhagen: WHO 1985.

7 Triebig G. Occupational neurotoxicity of organic solvents and solvent mixtures. Neurotoxicol Teratol 1989;11:575-8.

8 Emerson RG, Pedley TA. Somatosensory evoked potentials. In: Daly DD, Pedley TA, eds. Current practice of clinical electroencephalography. New York: Raven Press, 1990:679-700.

9 Chiappa K. Evoked potentials in clinical medicine. New York: Raven Press, 1985:203-77.

10 Arezzo JC, Schaumburg HH. Screening for neurotoxic disease in humans. Fournal of the American College of Toxicology $1989 ; 8: 147-55$.

11 Arezzo JC, Simson R, Brenna NE. Evoked potentials in the assessment of neurotoxicity in humans. Neurobehavioral Toxicology and Teratology 1985;7:299-304.

12 Dyer RS. The use of sensory evoked potentials in toxicology. Fundam Appl Toxicol 1985;5:25-40.

13 Moody L, Arezzo JA, Otto D. Evaluation of workers of early peripheral neuropathy: the role of existing diagnostic tools. Seminars in Occupational Medicine 1986;1:153-62.

14 Rebert ChS. Multisensory evoked potentials in experimental and applied neurotoxicology. Neurobehavioral Toxicology and Teratology 1983;5:659-71.

15 Otto DA. The use of sensory evoked potentials in neurotoxicity testing of workers. Seminars in Occupational Medicine 1986;1:175-83.

16 Mattson JL, Gorzinski SJ, Albee RR, Zimmer MA. Evoked potentials changes from 13 weeks of simulated toluene abuse in rats. Pharmacol Biochem Behav 1990;36:683-9.

17 Seppalainen AM, Savolainen K, Kovala K. Changes induced by xylene and alcohol in human evoked potentials. Electroencephalogr Clin Neurophysiol 1981;51:148-55.

18 Seppalainen AM, Laine A, Salmi T, Riihimaki V, Verkkala E. Changes induced by short-term xylene exposure in human evoked potentials. Int Arch Occup Environ Health 1989; 61:443-9.

19 Antti-Poika M, Ojala M, Matikainen E, Vaheri E, Juntunen J. Occupational exposure to solvents and cerebellar, brainstem and vestibular functions. Int Arch Occup Environ Health 1989;61:397-401.

20 Urban P, Lukáš E. Visual evoked potentials in rotogravure printers exposed to toluene. Br F Ind Med 1990;47:819-23.

21 Zegers de Beyl D, Delberghe X, Herbaut AG, Brunko E. The somatosensory central conduction time: physiological considerations and normative data. Electroencephalogr Clin Neurophysiol 1988;71:17-26.

22 Hume AL, Cant BR, Shaw NA, Cowan JC. Central somatosensory conduction time from 10 to 79 years. Electroencephalogr Clin Neurophysiol 1982;54:49-54

$23 \mathrm{Chu}$ NS, Hong CHT. Erb's and cervical somatosensory evoked potentials: correlations with body size. Elecroencephalogr Clin Neurophysiol 1985;62:319-22.

24 Pfanzagl J. Allgemeine Methodenlehre der Statistik II. Berlin: Walter de Gruyter, 1966:190-3.

25 Allison T, Wood CHC, Goff WR. Brainstem auditory, pattern reversal visual, and short-latency somatosensory evoked potentials: latencies in relation to age, sex, and brain and body size. Electroencephalogr Clin Neurophysiol 1983;55: 619-36.

26 Seppalainen AM, Harkonen H. Neurophysiological findings among workers exposed to styrene. Scand $\mathcal{f}$ Work Environ Health 1976;2:140-6.

27 Rosen I, Haeger-Aronsen B, Rehnstorm S, Welinder H. Neurophysiological observations after chronic styrene exposure. Scand f Work Environ Health 1978;4 (suppl 2):184-94.

28 Kovařík J, Pithartová R, Ehler E, Salandová J, Kużelová M, Popler A, Sirl J, Cihařová M. Health status of workers exposed to styrene used in manufacture of glass laminate. $S b$ Ved Lek Fak UK Hradec Králov Suppl 1989;32/5/:617-62. (In Czech with English summary.)

29 Cherry N, Gautrin D. Neurotoxic effects of styrene: further evidence. Br 7 Ind Med 1990;47:29-37. 
30 Triebig G, Schaller $\mathrm{KH}$, Valentin $\mathrm{H}$. Investigations on neurotoxicity of chemical substances at the workplace. VII. Longitudinal study with determination of nerve conduction velocities in persons occupationally exposed to styrene. Int Arch Occup Environ Health 1985;56:239-47.

31 Antti-Poika M, Juntunen J, Matikainen E, Suoranta H, Hanninen H, Seppalainen AM, Liira J. Occupational exposure to toluene: neurotoxic effects with special emphasis on drinking habits. Int Arch Occup Environ Health 1985;56: $31-40$.

32 Takahashi S, Kagawa M, Inagaki O, Akane A, Fukui Y. Metabolic interaction between toluene and ethanol in rabbits. Arch Toxicol 1987;59:307-10.

33 Crespi V, Boglium G, Delodovici ML. Peripheral ar d central conduction time in alcoholics. Electroencephaiogr Clin Neurophysiol 1987;S23:66/5/.

34 Arezzo JC, Schaumburg HH, Spencer PS. Structure and function of the somatosensory system: a neurotoxicologic perspective. In: Hayes AW, ed. Toxicology of the eye, ear and other special senses. New York: Raven Press, 1985:41-54.

35 Baker T. Electrophysiological correlates of sensimotor system neurotoxicology. Am Rev Pharmacol Toxicol 1986;26: $517-45$.

36 Chang YC. Neurotoxic effects of $n$-hexane on the human central nervous system: evoked potentials abnormalities in nhexane polyneuropathy. 7 Neurol Neurosurg Psychiatry 1987;50:269-74.

37 Kokubun Y, Oishi M, Taklesu T, Sakamaki S. SEPs in chronic alcoholics with spasticity. Arch Neurol 1988;45: 318-21.

38 Moller C, Odkvist L, Larsby B, Tham R, Ledin T, Bergholtz $\mathrm{L}$. Otoneurological findings in workers exposed to styrene. Scand 7 Work Environ Health 1990;16:189-94.

39 Hazeman P, Jeftic M, Lille F. Somatosensory evolked potentials in alcoholics and patients occupationally expcised to solvents and lead. Electroencephalogr Clin Neuroph vsiol 1987; 27:183-7.
40 Langauer-Lewowicka $\mathrm{H}$, Kazibutovska $\mathrm{Z}$, Zajac-Nadza $\mathbf{M}$ Value of short-latency somatosensory evoked potentials in the assessment of adverse effects due to carbon disulfide, inorganic lead and mercury vapour. Abstracts. Fifth international congress on neurotoxicology and occupational neurology. Prague, Czechoslovakia: 1990

41 Mutti A, Ferri F, Lommi G, Lotta S, Lucertini S, Franchini I. $\mathrm{N}$-hexane induced changes in nerve conduction velocities and somatosensory evoked potentials. Int Arch Occup Environ Health 1982;51:45-54.

42 Rosengren LE, Haglid KG. Long term neurotoxicity of styrene. A quantitative study of glial fibrillary acidic protein (GFA) and S-100. Br f Ind Med 1989;46:16-20.

43 Mutti A, Romanelli A, Falzoi M, Lucertini S, Franchini Styrene metabolism and striatal dopamine depletion in rabbits. Arch Toxicol Suppl 1985;8:447-50.

44 Mattia CJ, Bondy SC. Introduction of oxidative stress in the CNS by toluene. Book of abstracts p214. American Society for Neurochemistry, 23rd annual meeting, Houston, USA March 1992.

45 Rosenberg NL, Kleinschmidt-Memasters BK, Davis KA Dreisbach JN, Hormes JT, Filley CHM. Toluene abuse cases diffuse CNS white matter changes. Ann Neurol 1988;23:611-14.

46 Vliet van C, Swaen GMH, Slangen JJM, Boorder de TJ, Sturmans $\mathrm{F}$. The organic solvent syndrome. A comparison of cases with neuropsychiatric disorders among painters and construction workers. Int Arch Occup Environ Health 1987;59:493-501

47 Urban P, Lukáś E, Śtětkářová I. Correlations between EMG, $E E G, S E P$ and VEP examinations in toluene-exposed workers. Abstracts. Fifth international congress on neurotoxicolog and occupational neurology, Prague, Czechoslovakia: 1990.

Accepted 7 September 1992 